\title{
Bionomia dos estágios imaturos de duas espécies de Peckia (Diptera, Sarcophagidae) em suíno em decomposição em área de floresta no norte do Brasil
}

\author{
Aldenira Oliveira-da-Silva ${ }^{1}$, Rosaly Ale-Rocha ${ }^{1} \&$ José Albertino Rafael $^{1}$
}

${ }^{1}$ Coordenação de Pesquisas em Entomologia-Instituto Nacional de Pesquisas da Amazônia-INPA, Caixa Postal 478, 69011-970 Manaus-AM, Brasil. aldenira@inpa.gov.br, alerocha@inpa.gov.br\& jarafael@inpa.gov.br.

\begin{abstract}
Bionomics of the immature stages of two species of Peckia (Diptera, Sarcophagidae) in decomposed pig, in a forested area in northern Brazil. It was described the duration of larval instars of Peckia (Pattonella) smarti (Lopes 1941) and Peckia (Pattonella) pallidipilosa (Curran \& Walley 1934) obtained in pigs in natural environment during the rainy and dry seasons in the Forest Reserve Adolpho Ducke, Manaus, Amazonas. The larvae were put in containers with humid sawdust and pig meat with 12 hours of decomposition to pupate. The containers with the larvae were maintained in rearer close to the collection place. The identification was based on the adults and later they were correlated with the immatures. During the rainy season, the development period between the larval phase and the emergency were of 17.93 days to $P$. smarti and 15.87 days for $P$. pallidipilosa; in the dry season, 16.05 days for $P$. smarti and 15.96 days for $P$. pallidipilosa. Peckia smarti and P. pallidipilosa are being registered for the first time for the State of Amazonas and for Brazil, respectively.
\end{abstract}

KEYWORDS. Central Amazon; developmental stages; environmental condition; necrophagous.

RESUMO. Bionomia dos estágios imaturos de duas espécies de Peckia (Diptera, Sarcophagidae) em suíno em decomposição em área de floresta no norte do Brasil. Descreveu-se a duração dos estádios larvais de Peckia (Pattonella) smarti (Lopes 1941) e Peckia (Pattonella) pallidipilosa (Curran \& Walley 1934) obtidos em suínos em decomposição na natureza durante as estações chuvosa e seca na Reserva Florestal Adolpho Ducke, Manaus, Amazonas. As larvas foram colocadas em recipientes com serragem úmida e carne suína com 12 horas de decomposição para puparem. Os recipientes com as larvas foram mantidos em viveiro próximo ao local de coleta. A idenficação foi baseada nos adultos e posteriormente foram correlacionados com as larvas. O período de larva até a emergência dos adultos, na estação chuvosa, foi de 17,93 dias para $P$. smarti e 15,87 dias para $P$. pallidipilosa. Na estação seca foi de 16,05 dias para $P$. smarti e 15,96 dias para P. pallidipilosa. Peckia smarti e P. pallidipilosa estão sendo registradas pela primeira vez para o Estado do Amazonas e para o Brasil, respectivamente.

PALAVRAS-CHAVE. Amazônia Central; condições naturais; estágios do desenvolvimento; necrófagas.

O importante papel ecológico de decompositores valeu aos insetos um envolvimento direto na Entomologia Forense, uma associação da entomologia às questões legais e médicolegais (Catts \& Goff 1992).

Algumas contribuições a Entomologia Médico-criminal, relacionam-se a estudos sobre taxonomia, biologia e a ecologia dos insetos envolvidos no processo de decomposição cadavérica de humanos (Salviano et al. 1996). Outros trabalhos de sucessão ecológica utilizaram modelos experimentais de suínos para comparação com cadáveres humanos simulando situações de morte violenta (Payne 1965).

Os conhecimentos da diversidade, a freqüência das espécies nas diferentes épocas do ano e aspectos detalhados da biologia são dados utilizados na Medicina Legal podendo ser utilizados para revelar o modo, a causa e a localização da morte do indivíduo, como também estimar o tempo de morte (Payne 1965).

O objetivo deste trabalho foi estudar aspectos bionômicos das fases imaturas de duas espécies de Sarcophagidae (Diptera), Peckia (Pattonella) smarti e Peckia (Pattonella) pallidipilosa, que atuam na decomposição de animais.

\section{MATERIALE MÉTODOS}

O estudo foi conduzido na Reserva Florestal Adolpho Ducke, localizada na Rodovia Estadual AM-010, km-26, Manaus, Amazonas, Brasil, situada nos paralelos $02^{\circ} 55^{\prime}-03^{\circ} 01^{\prime} \mathrm{S}$ e 59 53'-59 59' W com área de 100 km² (Alencar 1994, Ribeiro et al. 1999). Foi escolhido para coleta, um ambiente com vegetação típica de platô, ou seja, com árvores variadas de grande porte (35-40 m) e muitas árvores emergentes além de áreas com coberturas muito densas de trepadeiras e arbustos.

O clima da região é marcado por duas épocas distintas. Assim, as coletas foram realizadas em dois períodos: abrilmaio de 2003 (estação chuvosa) e agosto-setembro de 2003 (estação seca). As coletas das larvas no suíno foram feitas diariamente nos primeiros dias desses meses entre 06:00 e 18:00 horas.

Para as coletas, foi usado cadáver de suíno (Sus scrofa L.) com aproximadamente $16 \mathrm{~kg}$. O animal era sacrificado no local de coleta com um tiro na parte frontal da cabeça, e deixado para decompor em gaiola de metal desmontável 2,00 m de largura e altura por 2,00 $\mathrm{m}$ de comprimento. A gaiola era coberta 
com tela de arame com malha de 2 polegadas, possuía porta na parte inferior, também revestida com tela de arame. A gaiola foi enterrada a aproximadamente $10 \mathrm{~cm}$, evitando a entrada de animais de pequeno porte (Fig. 1).

Em uma primeira etapa, procedeu-se a coleta das larvas de Sarcophagidae no animal morto. Posteriormente, essas larvas foram colocadas em copos plásticos $(360 \mathrm{ml})$ com 100g de carne suína (carne fresca descongelada na noite anterior) para estabelecer a duração dos estádios larvais e da pupa até a emergência do adulto.

Para o estudo da bionomia, foram capturadas, em cada larvipostura, 26 a 44 larvas de cada fêmea de Sarcophagidae sobre o cadáver, com auxílio de uma pinça fina. De cada amostra, foram separadas aproximadamente 10 larvas e colocadas em copos plásticos ( $360 \mathrm{ml}$ ) com 100g de carne suína (carne fresca descongelada na noite anterior) visando o reconhecimento das diferentes fases de desenvolvimento. Até 48 horas as observações biológicas foram realizadas em intervalos de duas horas, sob microscópio estereoscópico. Seis larvas de cada fêmea de Sarcophagidae foram fixadas em Kaad e conservadas em álcool 80\% para posterior análise e determinação da fase de desenvolvimento. Os estádios larvais foram caracterizados de acordo com o número de aberturas espiraculares e a presença ou não de espiráculos protorácicos (Knipling 1937). Ao atingir o $3^{\circ}$ estádio, as larvas foram transferidas para frascos plásticos transparentes de boca larga $(17 \mathrm{~cm}$ de altura x $13 \mathrm{~cm}$ de largura), contendo serragem fina e $250 \mathrm{~g}$ de carne suína, e tampados com tecido tipo organza, preso por um elástico nas bordas. Os frascos contendo as larvas foram mantidos no viveiro no campo, em temperatura ambiente, para completarem o ciclo (neolarva - adulto). Os adultos foram coletados manualmente e sacrificados para posterior identificação e associação com os imaturos.

A distribuição das chuvas em abril foi de 413,4, maio 359,8 mm e agosto 81,5 , em setembro foi de $53,4 \mathrm{~mm}$, de acordo com a Unidade de Pesquisa de âmbito Estadual de Manaus da Embrapa. A temperatura diurna no viveiro variou de 23,3 a $28,5^{\circ} \mathrm{C}$ na estação chuvosa (Fig. $2 \mathrm{~A}$ ); 23,7 a $28,7^{\circ} \mathrm{C}$ na estação seca (Fig. 2B). A umidade relativa diária no viveiro na estação chuvosa variou de 80,9 a $98,8 \%$ e de 78,6 a $99 \%$ na estação seca (Fig. 2A-B).

\section{RESULTADOS EDISCUSSÃO}

Foram examinadas 372 larvas na estação chuvosa (182 de P. smarti e 190 de $P$. pallidipilosa) e 373 larvas na estação seca (187 de $P$. smarti e 186 de $P$. pallidipilosa).

As fêmeas depositaram 44-54 neolarvas no cadáver do suíno. Foi observada preferência pelos orifícios naturais do animal, sendo $90 \%$ das larvas depositadas na boca e $10 \%$ no focinho, onde a intensidade e saturação de luz são menores e o teor de substância líquida mais elevado (Norris 1965).

As larvas do primeiro estádio são gregárias nas primeiras 5 horas. A partir do segundo estádio apresentam movimentos aleatórios e contínuos no substrato de criação. Segundo Stewart (1934), as larvas de moscas varejeiras, quando

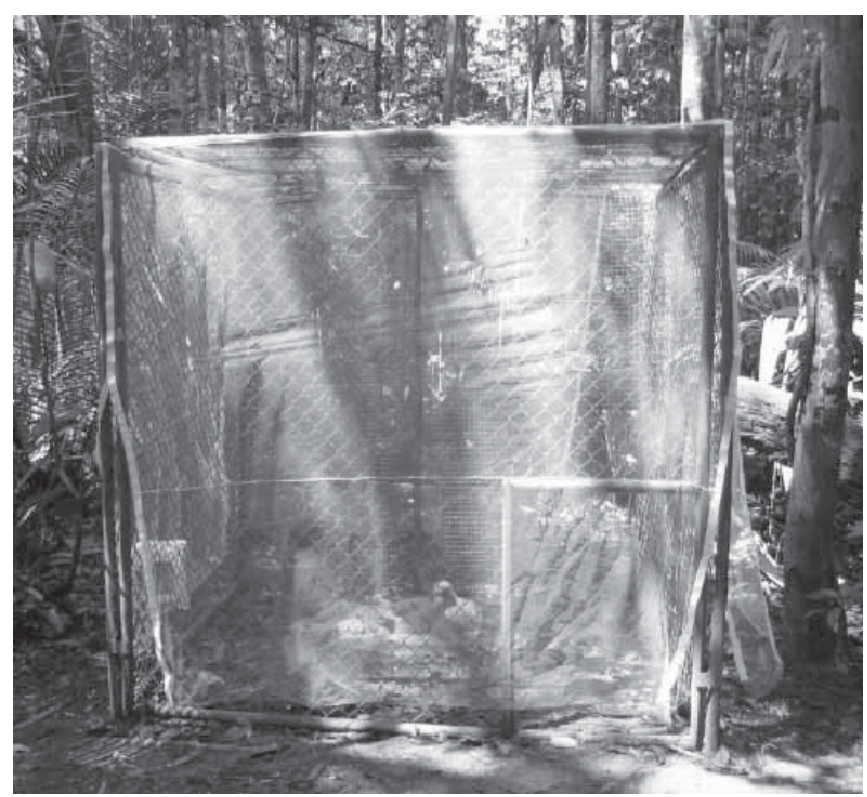

Fig 1. Aspecto geral da gaiola utilizada nas coletas, localizada na Reserva Florestal Adolpho Ducke, Manaus - AM.

colocadas em meio xênico, concentram-se em número relativamente grande em determinados locais. Estas observações sugerem que o comportamento de agregação no início do desenvolvimento pode facilitar a utilização do alimento, seja pela ação do calor metabólico ou pela liberação de enzimas ou substâncias, associadas ou não aos microorganismos, que atuam na degradação do alimento (Hanski 1987).

Peckia (Pattonella) smarti. A duração média do tempo de desenvolvimento dos $1^{\circ}, 2^{\circ}$ e $3^{\circ}$ estádios larvais no viveiro, durante a estação chuvosa, foi de 23 horas e $47 \mathrm{~min}, 15$ horas e 21 min e 15 horas e 43 min respectivamente, a $26^{\circ} \mathrm{C}$. A duração média do período da postura até a pré-pupa foi de 4,58 dias e pupa foi de 9,73 dias. O tempo médio de duração até a emergência do adulto foi de 17,93 dias a 26, $6^{\circ} \mathrm{C}$ (Fig. 3A).

Durante a estação seca, a duração média dos $1^{\circ}, 2^{\circ}$ e $3^{\circ}$ estádios larvais foi de 21:57 h, 13:52h (0,58 dias) e 13:22h ( 0,56 dias) respectivamente, a $26,6^{\circ} \mathrm{C}$. A duração média do período da postura até a pré-pupa foi de 3,82 dias e pupa foi de 6,27 dias. O tempo médio de duração até a emergência do adulto foi de 16,05 dias a $26,6^{\circ} \mathrm{C}$ (Fig. 3A).

O tempo médio de desenvolvimento da postura até a emergência do adulto foi maior na estação chuvosa a $26^{\circ} \mathrm{C}$ (17,93 dias) do que na estação seca (16,05 dias).

A umidade relativa baixa aparentemente exerce influência na velocidade de desenvolvimento de $P$. smarti, visto que na estação seca o tempo de desenvolvimento dos estágios imaturos foi mais curto do que na estação chuvosa, desenvolvendo-se em menor tempo sob condições de baixa umidade e baixa precipitação pluviométrica.

Peckia (Pattonella) pallidipilosa. A duração média do 
tempo de desenvolvimento dos $1^{\circ}, 2^{\circ}$ e $3^{\circ}$ estádios larvais durante a estação chuvosa foi de 25 horas e $49 \mathrm{~min}, 15$ horas e $30 \mathrm{~min}, 12$ horas e $15 \mathrm{~min}$ respectivamente, a $26^{\circ} \mathrm{C}$. A duração média do período da postura até a pré-pupa foi de 3,77 dias e pupa foi de 8,95 dias. O tempo médio de duração até a emergência do adulto foi de 15,87 dias a $25,9^{\circ} \mathrm{C}$. (Fig. 3B).

Durante a estação seca, a duração média dos $1^{\circ}, 2^{\circ}$ e $3^{\circ}$ estádios larvais foi de 21:47, 13:48h (0,58 dias) e 15:08h ( 0,63 dias) respectivamente, a $26,6^{\circ} \mathrm{C}$. A duração média do período da postura até a pré-pupa foi de 5,27 dias e pupa foi de 6,39 dias. O tempo médio de duração até a emergência do adulto foi de 15,96 dias a $26,66^{\circ} \mathrm{C}$. (Fig. 3B).

O tempo médio de desenvolvimento da postura até a emergência do adulto foi maior na estação chuvosa a $26^{\circ} \mathrm{C}$ ( 8,95 dias) do que na estação seca (6,39 dias).

P. pallidipilosa não mostrou variação significante na duração dos estágios imaturos nos diferentes períodos estudados, o que pode indicar que essa espécie sofre menor influência da umidade relativa e precipitação pluviométrica.

Não houve diferença no tempo de desenvolvimento dos estágios larvais das duas espécies nas duas estações estudadas. Após 15 horas de observação, nas duas estações, todas as larvas já se encontravam no $3^{\circ}$ estádio. Entretanto, observou-se diferença em relação à duração de pré-pupa de $P$. smarti e $P$. pallidipilosa nas duas estações.

Verificou-se que o tempo de desenvolvimento do adulto na estação seca teve pouca diferença para as duas espécies em estudo (Fig. 3A e 3B) provavelmente em função da variação
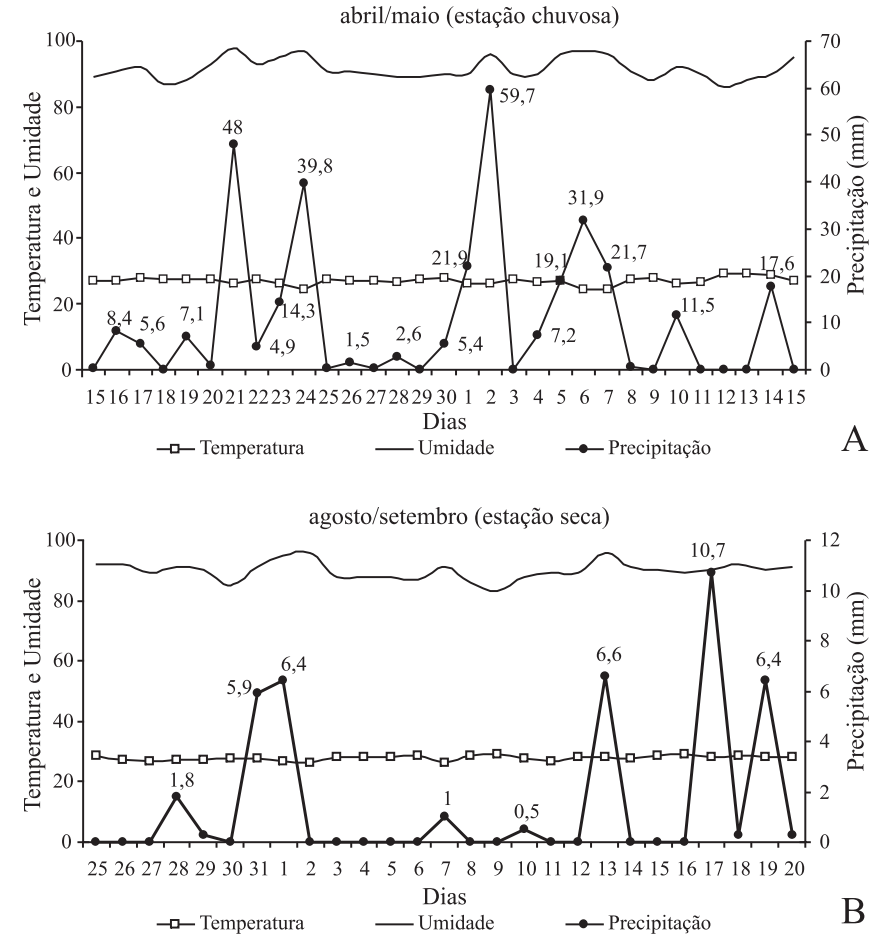

Fig 2. Médias diárias de temperatura $\left({ }^{\circ} \mathrm{C}\right)$ e umidade relativa (UR\%) medida no viveiro, de abril a maio/2003 (A) e agosto a setembro/2003 (B) e precipitação $(\mathrm{mm})$ da estação da EMBRAPA próximo à Reserva Florestal Adolpho Ducke, Manaus, AM.
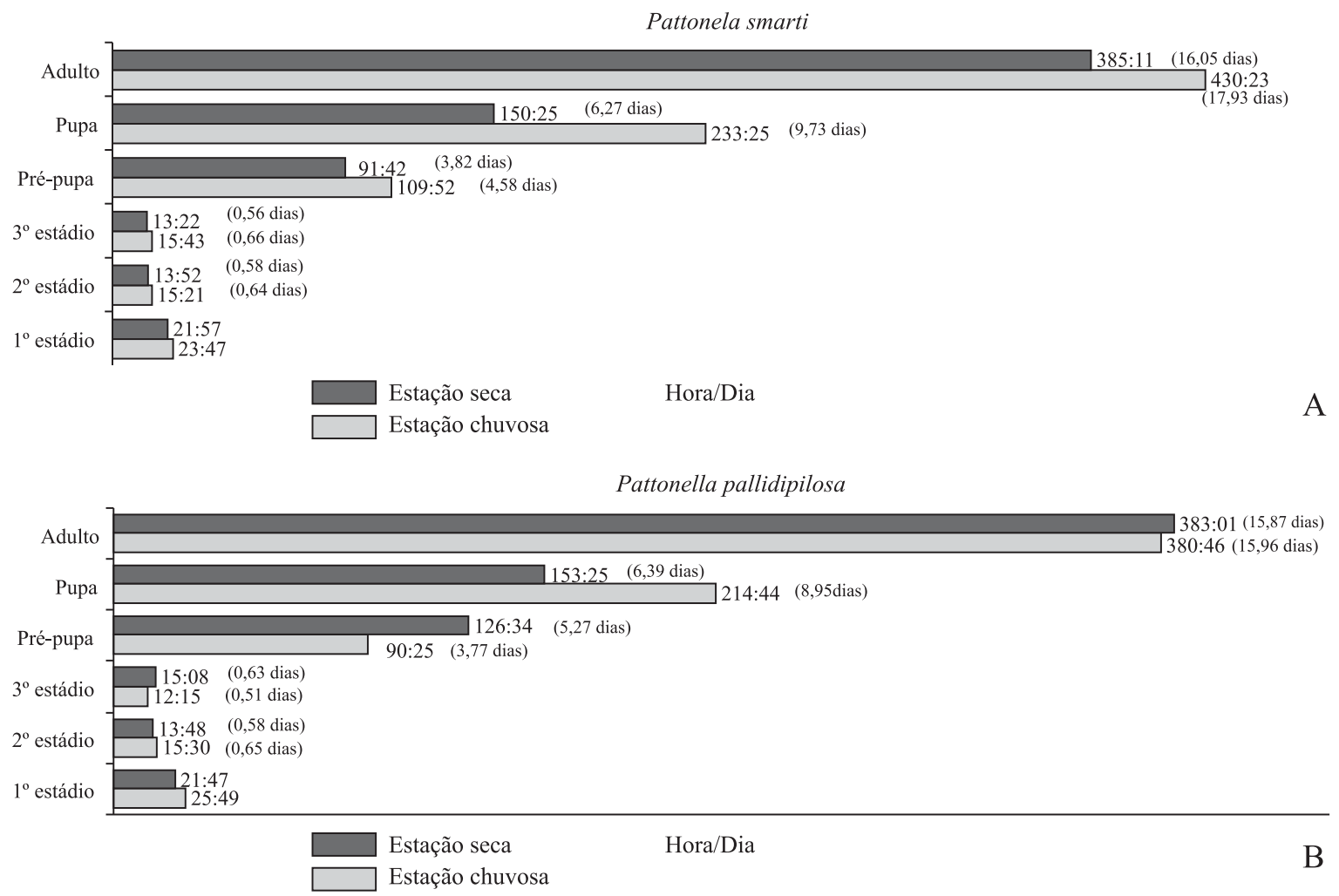

Fig 3. Tempo médio de desenvolvimento desde o $2^{\circ}$ estádio larval até a emergência do adulto de Peckia (Pattonella) smarti (A) e Peckia (Pattonella) pallidipilosa (B) durante a estação chuvosa e seca de 2003, em ambiente natural, na Reserva Florestal Adolpho Ducke, Manaus, AM. 
da temperatura e umidade relativa (Fig. 2B), que mostrou pouca flutuação durante o dia.

Salviano et al. (1996) relatam que espécies de sarcofagídeos de regiões tropicais apresentam diferenças biológicas quando estão em seus respectivos ambientes naturais, onde os fatores abióticos modificam-se constantemente ao longo do dia, e as suas necessidades alimentares não são limitadas ou excluídas, ao contrário do que ocorre quando criados em laboratório.

O desenvolvimento das larvas de Sarcophagidae foi observado no cadáver do suíno. $\mathrm{O}$ tempo decorrido desde a larvipostura até o $3^{\circ}$ estádio foi de 3 a 4 dias nas duas estações coincidindo com os dados obtidos no viveiro. As larvas permaneceram no cadáver até alcançar o $3^{\circ}$ estádio, quando se deslocavam cerca de $1 \mathrm{a} 2 \mathrm{~m}$ para empupar. Esta fase é decisiva para a sobrevivência da mosca, quando buscam uma superfície úmida, proteção contra predadores e outros inimigos naturais. Solos duros e excessivamente secos são fatais para a pré-pupa (Guimarães et al. 1983).

Logo que a mosca emerge através de uma abertura na porção média-anterior do pupário, apresenta o corpo mole, move-se vagarosamente e aos poucos vai endurecendo a cutícula, e suas asas ainda enroladas são expandidas vagarosamente por cerca de 30-45 minutos até que estejam totalmente prontas para o vôo. Essas observações foram semelhantes para os adultos emergidos provenientes das larvas criadas no viveiro e para adultos emergidos no solo.

$P$. smarti tinha sido registrada anteriormente para a Guiana, Brasil (Pará) e Peru e P. pallidipilosa para a Guiana (Pape, 1996). Estes representam os primeiros registros de $P$. smarti e P. pallidipilosa para o Estado do Amazonas e para o Brasil, respectivamente.

Agradecimentos. Ao bolsista Alexandre da Silva Filho, aos técnicos João Vidal e Jailson Vidal (INPA) pela ajuda no campo, ao Dr. José
Camilo Hurtado Guerrero (UEA) pela ajuda na confecção das matrizes e a Dra. Cátia Antunes de Mello-Patiu, (UFRJ) pela identificação do material.

\section{REFERÊNCIAS}

Alencar, J. C. 1994. Fenologia de cinco espécies arbóreas tropicais de Sapotácea correlacionada a variáveis climáticas na Reserva Ducke, Manaus, Amazonas. Acta Amazonica 24: 161-182.

Catts, E. P. \& M. L. Goff. 1992. Forensic Entomology in criminal investigations. Annual Review of Entomology. 37: 253-272.

Guimarães, J. H.; N. Papavero \& A. P. Prado. 1983. As miíases na região Neotropical: identificação, biologia e bibliografia. Revista Brasileira de Zoologia 1: 239-416.

Hansky, I. 1987. Nutricional ecology of dung and carrion feeding insects. In: F. Slansky Jr. \& J. R. Rodrigues (ed.) Nutritional ecology if insects, mites, spiders and related Invertebrates. An: Overwiew, N.Y. 1016 p.

Knipling, E. F. 1937. The Biology of Sarcophaga cistudinis Aldrich (Diptera). A species of Sarcophagidae parasitic on turtles and Tortoises. Proceedings of the Entomological Society of Washington 39: 91-101.

Norris, K. R. 1965. The bionomics of blow flies. Annual Review of Entomology 10: 47-68.

Pape, T. 1996. Catalogue of the Sarcophagidae of the world (Insecta: Diptera). Memoirs of Entomology International 8: 1-558.

Payne, J. A. 1965. A summer carrion study of the baby pig Sus scrofa Linnaeus. Ecology 46: 592-602.

Ribeiro, J. E. L.; M. J. G. Hopkins; A. Vicentini; C. A. Sothers; M. A. S. Costa; J. M. Brito; L. H. P. Martins; L. G. Lohmann; P. A. C. L Assunção; E. C. Pereira; S. M. R. Mesquita \& L. C. Procópio 1999. Flora da Reserva Ducke. Guia de identificação das plantas vasculares de uma floresta de terra-firme na Amazônia Central. Manaus. INPA, 799 pp.

Salviano, J. B. R.; P. R. Mello; C. N. H. L. Beck \& J. M. D'almeida 1996. Aspectos bionômicos de Squamatoides trivittatus (Diptera, Sarcophagidae) sob condições de laboratório. Memórias do Instituto Oswaldo Cruz 91: 249-254.

Stewart, M. A. 1934. The role of Lucilia sericata Meig. larvae in osteomyelitis wounds. Annals of Tropical Medicine and Parasitology 28: 445-460. 